\title{
False memories and fantastic beliefs: 15 years of the DRM illusion
}

\author{
David A. Gallo \\ University of Chicago, Chicago, Illinois
}

\begin{abstract}
This article reviews research using the Deese/Roediger-McDermott (DRM) associative memory illusion, whereby people falsely remember words that were not presented. This illusion has broadly influenced basic theories of memory in cognitive psychology and neuroscience and naturally raises the question as to how these theories apply to more complex autobiographical memories. Some applicability is evident from research linking individual differences in the DRM illusion to false autobiographical memories (e.g., misremembering public events) and fantastic autobiographical beliefs (e.g., memories from past lives). But which aspects generalize? Here it is argued that a process-oriented approach is needed in order to answer this question. Many productive years of DRM research indicate that multiple and often opposing psychological processes cause even the most basic false memories. In light of these discoveries, more researchers need to use methods that isolate these component processes if the goal is to understand false memories both in the lab and in life.
\end{abstract}

In the Deese/Roediger-McDermott (DRM) illusion, named after Deese (1959) and Roediger and McDermott (1995), people study lists of associated words (bed, rest, awake, etc.) and then take a free recall or recognition memory test. The typical finding is that people often falsely remember that nonstudied associates (sleep) were presented in the study lists. This memory illusion is difficult for people to avoid and has been used in hundreds of studies spanning many branches of psychological science. The goal of the present article is not to review every study and theory relevant to this illusion (for a more comprehensive review, see Gallo, 2006). The goal is to highlight the main theoretical problem that this research aims to solve, to summarize and update many of the key results, and to provide a critical progress report.

\section{The Problem: What Causes False Memories?}

The overarching goal of DRM researchers is to understand false memories. Deese (1959) originally reported the illusion, but it was not until Roediger and McDermott (1995) connected it to false memory that many researchers took notice (see Bruce \& Winograd, 1998). Roediger and McDermott (1995) demonstrated that some lists elicited very high levels of false memories that were accompanied with strong confidence and claims of remembering (Figure 1), as opposed to vague guesses or feelings of familiarity (cf. Tulving, 1985). Roediger and McDermott (1995) argued that the task was a reliable way to study false memories under carefully controlled laboratory conditions.

Despite this goal, the DRM illusion's relevance to other types of false memories has been questioned. Freyd and Gleaves (1996) admonished Roediger and McDermott's
(1995) suggestion that DRM findings apply to memories created in nonlaboratory settings. DePrince, Allard, Oh, and Freyd (2004) even argued that the term false memory should not be used for the DRM illusion, to avoid confusion with false-memory debates in autobiographical memory (i.e., the veracity of memories recovered in psychotherapy; see Gleaves, Smith, Butler, \& Spiegel, 2004; Kihlstrom, 2004; McNally, 2003; Pezdek \& Lam, 2007; Wade et al., 2007). One could easily defend the term false memory for the DRM illusion, ${ }^{1}$ but the more substantial question is how DRM research applies to autobiographical memories or to memories for events occurring outside the lab.

The issue of generalizability has not been addressed much in the DRM literature. Most researchers have either investigated questions about the phenomenon itself (e.g., under what conditions is the illusion reduced or enhanced?) or adopted the task as a basic measure of false memories to answer some related question (e.g., how are false memories instantiated in the brain?). These types of questions have yielded important insights that will be reviewed here, but the overarching goal in this review is to consider the implications of DRM research for our understanding of other kinds of false memories. Such generalizability may seem obvious to cognitive psychologists, but given the historical controversies surrounding false memories, as well as newer findings relevant to the issue, it may be time to revisit some basic assumptions.

Questions about generalizability ultimately stem from the complex differences between the lab and life. In their reply to Freyd and Gleaves (1996), Roediger and McDermott (1996) acknowledged that such issues could be "thorny" (p. 815). Indeed, in each of these articles, ex-

D. A. Gallo, dgallo@uchicago.edu 


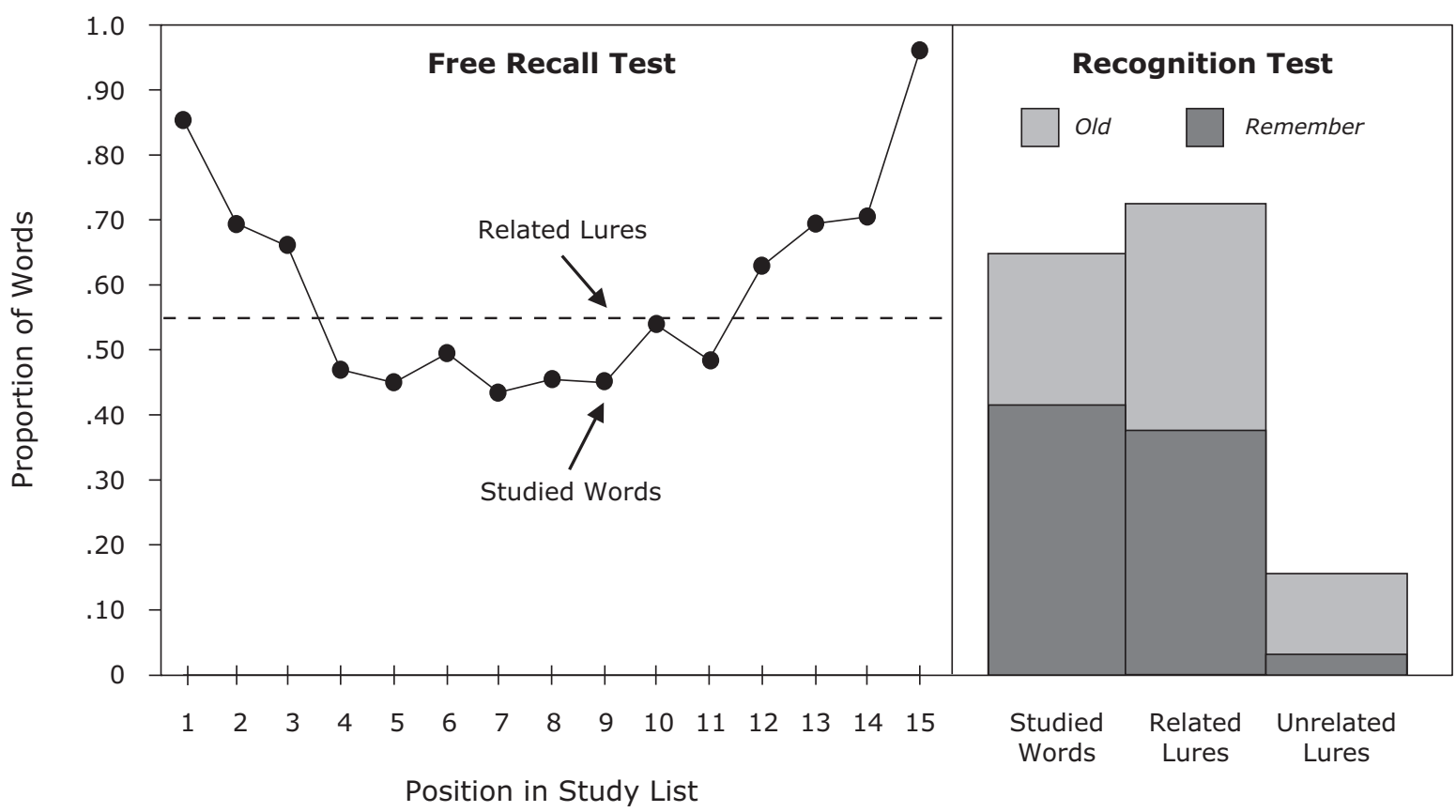

Figure 1. The DRM illusion. Undergraduates studied several lists of 15 words for immediate free recall (left panel) or for a final oldnew recognition memory test with remember subjective judgments (right panel). The data are from Experiment 2 of "Creating False Memories: Remembering Words Not Presented in Lists," by H. L. Roediger III and K. B. McDermott, 1995, Journal of Experimental Psychology: Learning, Memory, \& Cognition, 21, pp. 803-814. Copyright 1995 by the American Psychological Association. Reprinted with permission.

amples of how the DRM illusion differs from autobiographical memories are cited. Memories for word lists are, by design, more constrained and less complex than autobiographical memories along many dimensions (e.g., personal relevance, emotional salience, perceptual details, social context, etc.). These differences limit any wholesale generalization from one phenomenon to the other. For example, the finding that DRM false memories are easy to create is not evidence that false autobiographical memories are common, just as the finding that more perceptually detailed DRM false memories are difficult to create is not evidence that detailed false autobiographical memories are rare. Too many factors differ across these phenomena for such overarching generalities.

Setting aside the differences between the lab and life, researchers do assume that some of the principles uncovered with the DRM illusion apply more broadly. Otherwise, there would be little reason to do the research. As was argued by Roediger (1996), the DRM illusion informs our basic understanding of memory, just as visual illusions inform our understanding of perception. This research tradition embraces well-controlled laboratory tasks as an ideal method for developing theories (Banaji \& Crowder, 1989). As a result, most DRM research has been focused on basic theoretical distinctions within cognitive psychology, with generalizability either assumed as a given or set aside to be figured out elsewhere.

Within this research tradition, monolithic questions of generalizability such as whether the DRM illusion is rel- evant to false autobiographical memories are misguided. Instead, the appropriate questions to ask are what aspects of the DRM illusion are relevant to what aspects of autobiographical memories. More specifically, researchers have advocated a process-oriented approach. Which mental processes do these phenomena have in common, and which are unique? In what ways are these commonalities important, and in what ways are they trivial? These questions are addressed in subsequent sections of this review. Before I delve into this research literature, however, the broader historical context of DRM research is briefly considered. The DRM illusion has had a large impact on memory research, and understanding why helps to put the research findings in perspective. The task's simplicity has caused some to question its generalizability, but somewhat ironically, this simplicity is one of the reasons that the task has been so successful.

\section{Impact: How DRM Changed Memory Research}

Roediger and McDermott's (1995) article is immensely popular, having been cited over 1,000 times. In the first decade following the article, the average rate of newly published DRM experiments was estimated as one experiment every 2 weeks (Gallo, 2006), and in the few years since then, citations have almost doubled. That is quite an impact by any standard, but why is this task so popular? What is new about it?

DRM research has enhanced awareness of the fallible nature of memory. This impact is evident from coverage in 
introductory psychology textbooks, as well as in the popular press (e.g., Grierson, 2003). Of course, psychologists have contemplated memory distortion ever since experimental psychology split from philosophy (e.g., Burnham, 1889; Munsterberg, 1908), and many laboratory techniques used to study false memory predate the DRM illusion (for reviews, see Roediger, McDermott, \& Robinson, 1998; Schacter, 1995). For example, research distorting eyewitness memory or memory for childhood events has had a large and invaluable impact (see Hyman \& Loftus, 2002; Loftus, 2005). The main advantage of the DRM illusion over these other approaches is that the DRM task provides a much simpler way to demonstrate false memories. Just as the Stroop task is a classic demonstration of interference, the DRM task is a compelling demonstration of false memories.

DRM research also has enhanced awareness of the constructive nature of memory. Some have argued that the DRM illusion reflects an adaptation to informationprocessing limits, whereby people retain only the meaning or associations of what they encounter and reconstruct the rest (e.g., Roediger \& McDermott, 2000; Schacter, 2001). By this view, falsely remembering a word that is associated with studied words is merely an unwanted byproduct of otherwise useful heuristics, analogous to other cognitive illusions (Pohl, 2004). Earlier experimental demonstrations of useful reconstructive processes in memory include Bartlett's (1932) schema studies and Brewer's (1977) inference work, among others. What was new and even surprising about the DRM illusion was that constructive processes could be involved in a simple wordlist memorization task, which was more typically considered to involve rote or reproductive memory. Roediger and McDermott (1995) argued that the illusion showed how all aspects of memory, including even the most basic tasks, involved constructive processes (for related ideas, see D. M. Bernstein \& Loftus, 2009; Johnson, 2006).

In addition to these conceptual contributions, the simplicity of the DRM task makes it relatively easy to conduct false-memory experiments with a high degree of experimental control. Researchers quickly adopted this task to study false memories in a variety of domains, including neuroimaging, neuropsychology, development, aging, and individual differences. The DRM illusion was swept up by, and contributed to, a false-memory zeitgeist (see Bruce \& Winograd, 1998). As Koriat, Goldsmith, and Pansky (2000) put it, the DRM task was part of a more general trend in memory research toward understanding the factors that influence retrieval quality (over quantity). This trend started well before the DRM illusion, but the DRM illusion helped catalyze the movement, and it fostered a more integrative cognitive neuroscience of memory accuracy (see Schacter, Norman, \& Koutstaal, 1998).

\section{Trajectory: What We Know About the Problem}

DRM research has attempted to determine the causes of false memory at two levels. At the most basic level, much of the research has been directed at understanding the cognitive and neural processes giving rise to the DRM illusion itself. At a more applied level, several studies have investigated possible links between the DRM illusion and autobiographical memory phenomena. These studies are fewer in number, but they provide unique insight into the generalizability problem. The significant advances in these two areas are reviewed next, starting with basic research about the DRM illusion itself.

Establishing the illusion. The first point to take from basic research is that the DRM illusion is robust to a variety of manipulations. The size of the illusion is typically measured by a relatedness effect, the probability of falsely recalling or recognizing the nonstudied associate (or related lure) above an unrelated baseline. ${ }^{2}$ These DRM relatedness effects have persisted across a variety of encoding tasks, retention intervals, and test formats. They have also been observed in a variety of populations, including the young, the old, the neurologically impaired, and people with different languages and cultures. The reliability of this illusion highlights the relatively automatic nature of associative processes in memory.

The second point to take from basic research is that the DRM illusion truly reflects a false memory, defined here as the recollection of something that did not happen. To understand this point, it is helpful to consider the alternative. Drawing from signal detection theory, Miller and Wolford (1999) argued that the DRM illusion might be caused by a liberal response bias toward any word that appeared to be related to the study list, as opposed to the retrieval of information that causes an actual false memory (i.e., a falsememory signal). Subjects may simply guess or infer that the related lure was in the study list because it is strongly associated to the studied words. Wixted and Stretch (2000) argued against Miller and Wolford's particular analysis and showed how signal detection theory could also support a false-memory account (in particular, they noted that estimates of response bias can be ambiguous). Nevertheless, the possibility that the DRM illusion could be caused by an associatively based guessing strategy is an important theoretical question to empirically test.

At least five lines of evidence indicate that the DRM task produces false memories and not simply biases or guessing strategies: (1) Subjective judgments indicate that subjects recollect the related lure from the study list, including remember judgments (e.g., Roediger \& McDermott, 1995; but see Geraci \& McCabe, 2006), detailed ratings on the Memory Characteristics Questionnaire (e.g., Mather, Henkel, \& Johnson, 1997), and attributions to a particular study voice or modality (e.g., Payne, Elie, Blackwell, \& Neuschatz, 1996). (2) The DRM illusion (and subjective judgments) can be reduced but not eliminated by explicit warnings to avoid the illusion or by giving contrary demand characteristics (e.g., Gallo, Roediger, \& McDermott, 2001; Neuschatz, Payne, Lampinen, \& Toglia, 2001). Thus, although bias can influence the effect, the illusion persists in the face of opposing motivation. (3) An illusory subjective experience has been objectively estimated from modeling procedures (see Brainerd, Wright, Reyna, \& Mojardin, 2001). (4) Subjects have difficulty choosing between a studied word and the related lure on forced-choice tests that minimize response bias (Westerberg \& Marsolek, 2003). (5) Many studies have 
shown significant priming of the related lure on implicit memory tests that are unlikely to be influenced by associative guessing strategies (e.g., McDermott, 1997). Priming does not address illusory phenomenology, but it indicates that some mental representation for the nonstudied associate is activated, which is an important component of falsememory theories.

Activation/monitoring framework. The theoretical processes that cause the DRM illusion have been divided into an activation/monitoring framework (e.g., Roediger \& McDermott, 2000; Roediger, Watson, McDermott, \& Gallo, 2001). A very general interpretation of this framework will be adopted here. Activation describes any process that mentally activates the related lure or otherwise contributes to the retrieval of potentially false information (i.e., a false-memory signal). Monitoring describes any memory editing or decision process that helps to determine the origins of this activated information. Whereas activation enhances false memories, monitoring reduces them. This framework was motivated, in part, by experimental dissociations that revealed competing processes in the DRM task (e.g., Benjamin, 2001; McDermott \& Watson, 2001; see Figure 2). As can be seen in the review below, there is decent evidence for multiple kinds of activation and multiple kinds of monitoring in the DRM task.

Understanding activation. There are two dominant conceptualizations of activation in the DRM task. The associative-activation theory emphasizes spreading activation between preexisting conceptual representations in a mental lexicon (e.g., Roediger, Balota, \& Watson, 2001). Associative activation could occur when the list words are initially studied, or it could occur as list words are retrieved at test (see Meade, Watson, Balota, \& Roediger, 2007). This theory was endorsed in initial descriptions of the activation/monitoring framework (e.g., Roediger, Balota, $\&$ Watson, 2001), and it resonates with earlier associative

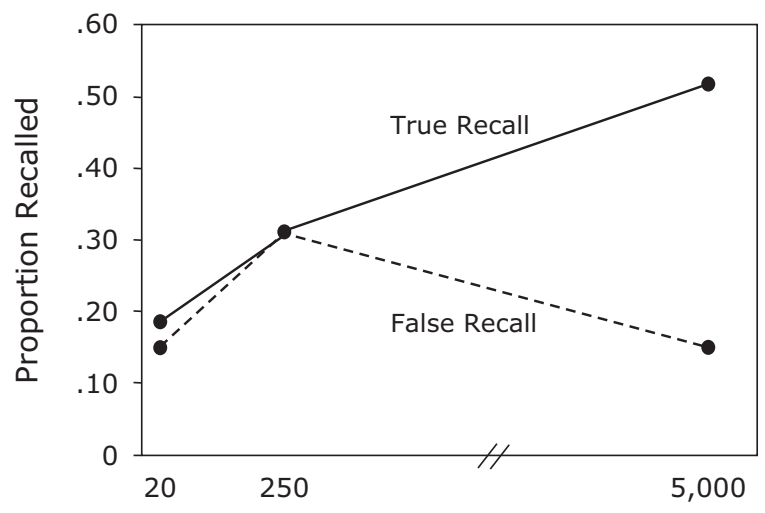

Study Presentation Duration (msec/word)

Figure 2. A dissociation between true and false recall, indicating that multiple processes contribute to the DRM illusion. The data are from "The Rise and Fall of False Recall: The Impact of Presentation Duration," by K. B. McDermott and J. M. Watson, 2001, Journal of Memory \& Language, 45, pp. 160-176. Copyright 2001 by Elsevier. Reprinted with permission. theories (Deese, 1959; Underwood, 1965). In contrast, the gist theory proposes that subjects mentally construct a gist representation during the study phase (e.g., Brainerd \& Reyna, 1998; Schacter, Verfaellie, \& Pradere, 1996). This representation summarizes the common semantic features or theme of the studied words and activates the related lure because it has similar features. The idea of a gist representation is endorsed by fuzzy trace theory, which has been implemented in a corresponding mathematical model (e.g., Brainerd \& Reyna, 1998, 2005; Brainerd, Reyna, Wright, \& Mojardin, 2003; Brainerd et al., 2001). ${ }^{3}$

The associative-activation and gist theories are difficult to tease apart in practice, but these processes are not mutually exclusive, and there is evidence that uniquely supports each. Some evidence that supports the associativeactivation theory is (1) the strong positive correlation between the degree of associative strength and the level of false memory across DRM lists (e.g., Deese, 1959; Roediger, Watson, et al., 2001; but see Brainerd, Yang, Reyna, Howe, \& Mills, 2008); (2) DRM lists elicit higher levels of false memory than do categorized lists (e.g., exemplars of the bird category), which are high in gist but do not have the same associative structure (e.g., Buchanan, Brown, Cabeza, \& Maitson, 1999; Pierce, Gallo, Weiss, \& Schacter, 2005; see also Park, Shobe, \& Kihlstrom, 2005); (3) associative strength is a better predictor of false recall than some manipulations of gist-based processing (e.g., Howe, Wimmer, Gagnon, \& Plumpton, 2009; Hutchison \& Balota, 2005); and (4) combining phonological and semantic associates in the study list has over-additive effects on false memory, ostensibly because of converging associative activation (Watson, Balota, \& Roediger, 2003).

Some evidence that supports the gist theory is that (1) false recall and recognition tend to be less affected by retention interval than true recall and recognition, consistent with the idea of a more robust gist trace (e.g., Toglia, Neuschatz, \& Goodwin, 1999); (2) including unrelated items on a recognition test enhances false recognition, relative to a test with only associated items, ostensibly by encouraging gist-based responding (e.g., Gunter, Ivanko, \& Bodner, 2005); and (3) false recognition occurs for perceptually similar pictures of the same object (e.g., Koutstaal \& Schacter, 1997) and even for abstract pictures that are perceptually similar but have no meaning or preexisting semantic associations (e.g., Koutstaal, Schacter, Verfaellie, Brenner, \& Jackson, 1999). These last findings do not involve the DRM task, but they do indicate that gist or feature-based processes can cause false recognition in the absence of preexisting associations.

Regardless of the particular type of activation, there is ample evidence that semantic processing drives the DRM illusion. Focusing attention on the relevant semantic features of study words increases false memory, as with levels of processing manipulations (e.g., Thapar \& McDermott, 2001), relational processing manipulations (McCabe, Presmanes, Robertson, \& Smith, 2004), and pairing each study word with a converging association (e.g., Thomas $\&$ Sommers, 2005). Blocking the study words by semantic associations also enhances false memory (e.g., McDermott, 1996), as does increasing the number of se- 
mantic associates studied in each list (e.g., Robinson \& Roediger, 1997). Finally, people with category-specific expertise are more prone to false recall from that same category (Castel, McCabe, Roediger, \& Heitman, 2007), and similarly, the DRM illusion is most likely when the study lists are presented in a speaker's dominant language (Anastasi, Rhodes, Marquez, \& Velino, 2005). Even more manipulations could be cited, but the conclusion would be the same: Increasing the likelihood that the relevant semantic associations will be processed increases activation, and increasing activation increases the DRM illusion.

An interesting question related to activation is whether the related lure is consciously generated during the study phase. The results of experiments in which subjects overtly rehearse during study indicate that conscious activation of the related lure does occur and is positively related to the strength of the illusion (e.g., Seamon et al., 2002). Conscious activation at study has also been inferred from retrospective subjective reports (e.g., Multhaup \& Conner, 2002) and implicit priming effects (e.g., Lövdén \& Johansson, 2003) and, less directly, from situations in which related lures behave like presented words, as in word frequency effects (Anaki, Faran, Ben-Shalom, \& Henik, 2005), retrieval induced forgetting effects (e.g., Bäuml \& Kuhbandner, 2003), and part-list cuing effects (e.g., Reysen \& Nairne, 2002). However, overt rehearsal experiments also indicate that conscious activation at study is not necessary for the illusion, as do conditions that discourage conscious activation at study, such as certain incidental encoding tasks (Dodd \& MacLeod, 2004) or extremely rapid presentation of the studied words (e.g., Seamon, Luo, \& Gallo, 1998; see Cotel, Gallo, \& Seamon, 2008). Thus, conscious activation of the related lure during study can strengthen the illusion, but it is not necessary for the illusion. As is described in the next section, conscious activation of the lure at study might even suppress the illusion, depending on the types of monitoring processes engaged.

It is important to note that much of the evidence for activation processes has been focused on false recall or recognition errors, but these errors are not synonymous with the subjective experience of illusory recollection. Illusory recollection frequently accompanies false recall or recognition in the DRM task, but these errors sometimes arise from weaker forms of subjective experience (e.g., vague feelings of familiarity). Despite this ambiguity, variables that increase false recall or recognition also tend to increase illusory subjective experience (e.g., Brainerd et al., 2001; Gallo \& Roediger, 2003; Mather et al., 1997; also see Arndt, 2006; Hicks \& Starns, 2006). These findings suggest that the same activation processes that contribute to false recall and recognition are also involved in creating the subjective content of illusory recollection. One idea is that detailed features become detached from studied items and attached to the false memory of the related lure (e.g., content borrowing; see Lampinen, Ryals, \& Smith, 2008; Lyle \& Johnson, 2006). A similar process (called phantom recollection) has been proposed in fuzzy trace theory, whereby gist information gets conflated with details from actually presented items (see Brainerd et al., 2001).
Alternatively, subjects might imagine the related lure's study presentation at test, in an effort to make a memory decision, and the subjective contents of this imagination may be falsely attributed to an actual memory (see Gallo \& Roediger, 2003; cf. Jacoby, Kelley, \& Dywan, 1989; Whittlesea, 2002). Attribution processes are intriguing because they show the tight relationship between activation and monitoring processes. Very little work has been done to test between these and other theories of illusory recollection, even though illusory recollection is the defining feature of false memories.

Understanding monitoring. A common idea in many memory frameworks is that enhancing true recollection can decrease false memory through some sort of monitoring process. The activation/monitoring framework generally appeals to the types of processes described within the source-monitoring framework (e.g., Johnson, Hashtroudi, \& Lindsay, 1993; Johnson \& Raye, 1981; see also Roediger \& McDermott, 2000). The fuzzy trace theory also includes a type of retrieval monitoring process, called recollection rejection, through which specific details from studied items can counteract the ability of gist representations to cause false memory (e.g., Brainerd et al., 2003). This latter proposal is similar but not identical to the distinction between recollection-based and familiarity-based responding proposed by dual-process theories of recognition memory (e.g., Jacoby, 1991; for a review, see Yonelinas, 2002).

Drawing from these frameworks, Gallo $(2004,2006)$ argued that all recollection-based monitoring could be divided into two classes, depending on the logic of the underlying decision process. Diagnostic monitoring relies on expectations to make a memory decision. When a questionable event fails to elicit recollections that are expected from its prior occurrence, it is rejected as false (e.g., "I didn't take the train home last Thanksgiving, because train rides are distinctive and I would remember that"). Diagnostic decisions are primary because they focus on the quality of the memorial evidence for the questionable event itself and whether this evidence passes some expected criteria. Disqualifying monitoring relies on collateral information to make a memory decision. When a questionable event elicits recollections that are inconsistent with its prior occurrence, it is rejected as false (e.g., "I didn't take the train home last Thanksgiving, because I remember taking an airplane instead"). Disqualifying decisions are secondary because they rely on collateral information and whether this information confirms or disqualifies the questionable event. Focusing on these two different types of decision processes helps to understand many empirical patterns in the DRM task and other tasks.

The idea that people engage in diagnostic monitoring or the use of expectations in memory decisions - has been used to explain findings in numerous tasks (e.g., Brown, Lewis, \& Monk, 1977; Johnson, Raye, Foley, \& Foley, 1981; Strack \& Bless, 1994; cf. Ghetti, 2003). This type of monitoring is a foundational tenet of the source-monitoring framework, which assumes that recollected features can vary in quality and vividness and that these differences are flexibly used in memory decisions (Johnson et al., 
1993). It also is compatible with some aspects of multidimensional signal detection theories (e.g., Banks, 2000; Hautus, Macmillan, \& Rotello, 2008; Slotnick \& Dodson, 2005), at least to the extent that people use expectations to establish the types of retrieved information and response criteria that are relevant to a memory decision.

Within the DRM illusion, Schacter and colleagues highlighted the use of expectations in research on the distinctiveness heuristic (e.g., Schacter, Israel, \& Racine, 1999). They found that presenting each studied word with a pictorial representation reduced the DRM illusion relative to the typical verbal-only procedure. According to the theory, subjects expected pictures to elicit more distinctive recollections than words, and so the absence of a picture recollection for related lures was more informative (or diagnostic) that the item had not been studied. Other evidence supports this monitoring interpretation, as opposed to the idea that picture encoding reduced activation (e.g., Arndt \& Reder, 2003; Hege \& Dodson, 2004). First, Schacter et al. (1999) found that picture encoding reduced false recognition when manipulated between subjects but not within subjects (and across lists). Even though activation differences should have been found in either condition, it was argued that subjects were more likely to expect distinctive recollections when pictures were studied for every list. Second, Dodson and Hege (2005) found that the picture encoding effect was eliminated on a speeded recognition test $(750 \mathrm{msec})$ that was thought to minimize monitoring but not activation (also see Schacter, Cendan, Dodson, \& Clifford, 2001). Finally, as predicted by the monitoring account, expecting picture recollections reduces memory errors in tasks that do not involve semantic activation (e.g., Dodson \& Schacter, 2002; Gallo, Weiss, $\&$ Schacter, 2004). For example, Gallo et al. (2004) found reduced source-memory confusions when test decisions were oriented toward picture recollections than when they were oriented toward word recollections, even though the same types of items were tested in each condition.

Many other manipulations that reduce the DRM illusion may involve diagnostic monitoring, to the extent that they enhance recollective distinctiveness but have little effect on activation (or increase it). These include various encoding manipulations, such as study modality (e.g., Smith \& Hunt, 1998), study vocalization (e.g., Dodson \& Schacter, 2001), study transcription (Seamon et al., 2003), study generation (e.g., Gunter, Bodner, \& Azad, 2007), study repetitions (e.g., Benjamin, 2001), and study rate (e.g., McDermott \& Watson, 2001). Various characteristics of the related lure also reduce false-memory rates, potentially because these characteristics enhance the expectation that the lure would elicit a strong recollection if it had been studied. These include emotionally taboo words (e.g., Pesta, Murphy, \& Sanders, 2001; Starns, Cook, Hicks, \& Marsh, 2006), long words (Madigan \& Neuse, 2004), and concrete words (Pérez-Mata, Read, \& Diges, 2002). Note, however, that most of these manipulations have not been studied as extensively as the picture encoding effect, and so processes other than diagnostic monitoring may be involved.
The idea that people engage in disqualifying monitoring - or the use of disconfirming evidence in memory decisions - is found in several tasks that have been used to support dual-process frameworks (see Yonelinas, 2002). These tasks include list-based exclusion (e.g., Jacoby, 1991), repetition lag (e.g., Dodson \& Schacter, 2002), changed pluralization (e.g., Hintzman \& Curran, 1994), associative recognition (e.g., Yonelinas, 1997), and conjunction recognition (e.g., Jones \& Jacoby, 2001). In many of these cases the term recall-to-reject has been used, and this term is somewhat synonymous with disqualifying monitoring. However, at least theoretically, it is possible that recalling studied items can inform retrieval expectations, thereby affecting diagnostic monitoring as well. Disqualifying monitoring is consistent with some aspects of multinomial models (e.g., Buchner, Erdfelder, \& Vaterrodt-Plünnecke, 1995; Jacoby, 1998), at least to the extent that the outcome of one retrieval process (i.e., whether or not disqualifying recollection is successful) can lead to either the rejection of an event or the need to engage additional retrieval processes (i.e., diagnostic monitoring) before making a decision.

The use of disqualifying monitoring processes can explain at least three different effects in the DRM task and related tasks. First, warning the subjects to avoid the DRM illusion before the study phase reduces (but does not eliminate) the illusion (e.g., Gallo, Roberts, \& Seamon, 1997). Evidence suggests that forewarning causes subjects to try to identify the related lure and then encode it as "not presented." The subsequent recollection of this information allows subjects to disqualify the item from having occurred (see Neuschatz, Benoit, \& Payne, 2003). Such monitoring may occur even when subjects are not explicitly warned about the illusion (Carneiro, Fernandez, \& Dias, 2009). Second, actually presenting the related lure in a to-be-excluded list helps subjects avoid falsely remembering this item (e.g., Dodhia \& Metcalfe, 1999; Gallo, Bell, Beier, \& Schacter, 2006). Recollecting the lure from the exclusion list allows subjects to disqualify the item as having occurred in the DRM list. Finally, subjects are less likely to falsely recognize a related lure when they can exhaustively recall all of the studied words from a category, likely because exhaustive recall disqualifies the related lure as also having been presented (Gallo, 2004). In all of these cases, it can be argued that the related lure was rejected on the basis of the successful recollection of some disqualifying information, as opposed to some activation difference or diagnostic monitoring process.

Neural processes. Researchers have discovered different neural underpinnings of activation and monitoring processes in the DRM illusion. As might be expected from fMRI studies of meaning extraction from language (e.g., Hasson, Nusbaum, \& Small, 2007), left inferior prefrontal and lateral temporal regions are active when subjects process the semantic associations in DRM lists (McDermott, Watson, \& Ojemann, 2005). These regions likely play a role in the activation of the related lure. Kim and Cabeza (2007a; also see Kubota et al., 2006) showed that encoding-related fMRI activity in the left ventrolat- 
eral prefrontal cortex (PFC) predicted subsequent true and false memory for short categorized lists, and Gallate, Chi, Ellwood, and Snyder (2009) found that regional transcranial magnetic stimulation near the lateral temporal lobes reduced the DRM illusion.

Evidence also links the medial temporal lobes (MTL) to activation processes in the DRM task. Damage to these regions causes autobiographical memory amnesia and also reduces true and false memory in the DRM task (e.g., Schacter et al., 1996; Van Damme \& d'Ydewalle, 2009) and in related tasks (e.g., Koutstaal et al., 1999). Analogous findings have been found in patients with Alzheimer's disease, which disproportionately affects MTL regions in the early stages (e.g., Budson, Daffner, Desikan, \& Schacter, 2000; Budson, Desikan, Daffner, \& Schacter, 2001). Neuroimaging studies also have implicated MTL regions in the DRM illusion. Cabeza, Rao, Wagner, Mayer, and Schacter (2001) found equivalent fMRI activity in the hippocampus when remembering studied words and also when falsely recognizing related lures relative to unrelated lures. This activity potentially reflected the retrieval of associations or gist that could activate the related lure, although it may also have reflected the retrieval of true memories in an attempt to monitor. Because both activation and monitoring processes contribute to the DRM illusion, neural activity to related lures can be ambiguous.

Compared with the PFC and MTL regions that have been linked to activation, different $\mathrm{PFC}$ regions have been implicated in monitoring. Budson et al. (2002) found that patients with lesions in dorsolateral PFC were more susceptible to the DRM illusion than control subjects, with little difference in true recognition. Melo, Winocur, and Moscovitch (1999) reported similar patterns in a smaller group of nonamnesic frontal patients, but amnesic frontal patients exhibited patterns that were more similar to MTL amnesics (also see Ciaramelli, Ghetti, \& Borsotti, 2009). These findings suggest that some types of PFC damage may impair monitoring, as has been argued in the literature on autobiographical confabulation, whereas others may have a more amnesic effect. Neuroimaging studies also indicate that the dorsolateral PFC is critical for retrieval monitoring. Cabeza et al. (2001) found greater fMRI activity in the dorsolateral PFC for studied words and related lures, relative to unrelated lures (also see Kim \& Cabeza, 2007b), and the dorsolateral PFC has been implicated in tasks that, unlike DRM, were specifically designed to isolate retrieval monitoring processes (e.g., Gallo, McDonough, \& Scimeca, 2010; for a review, see Rugg, 2004).

Normal aging-related increases in the DRM illusion also support the idea that the PFC supports retrieval monitoring processes, because PFC function is thought to decline disproportionately in older adults (e.g., Balota et al., 1999). In fact, aging-related increases in the DRM illusion are largest in conditions that place a high demand on retrieval monitoring (e.g., Gallo, Bell, et al., 2006; Kensinger \& Schacter, 1999) or in older adults that have reduced frontal functioning (e.g., Butler, McDaniel, Dornburg, Price, \& Roediger, 2004). One caveat to this conclusion is that older adults can monitor memory very effectively when more distinctive recollections are available (e.g., Gallo, Cotel, Moore, \& Schacter, 2007; Schacter et al., 1999), potentially because these situations place fewer demands on prefrontal resources (e.g., Gallo, Kensinger, \& Schacter, 2006). Consistent with the relatively late development of $\mathrm{PFC}$, there is evidence for reduced monitoring in children as well (e.g., Carneiro \& Fernandez, 2010; for a review and commentary, see Brainerd, Reyna, \& Ceci, 2008; Ghetti, 2008; Howe, 2008). However, unlike older adults, young children show reduced relatedness effects in the DRM task, potentially reflecting underdeveloped semantic networks or gist-based processing (e.g., Brainerd, Reyna, \& Forrest, 2002). These developmental patterns provide additional evidence for the complex interplay between activation and monitoring processes in the DRM task.

Neuroimaging studies of the DRM task also have shown differences between true and false memories. For example, Schacter et al. (1996) found greater PET activity in the auditory cortex when subjects were (visually) tested for studied words but not for related lures. This activity potentially reflected the recollection of the voice that had initially presented the studied words (see also Abe et al., 2008; Cabeza et al., 2001). Fabiani, Stadler, and Wessels (2000) presented studied words to the right or left of fixation. They found a corresponding lateralization of ERP effects when these studied words were presented centrally at test, and this effect was not observed for related lures. In general, such differences are attributed to recollected details that could be used to differentiate true and false memories during monitoring, although other explanations are possible (see Schacter \& Slotnick, 2004).

Autobiographical links. It is generally assumed that some of the processes contributing to the DRM illusion also contribute to false autobiographical memories. If this assumption is valid, variables affecting these underlying processes should affect both types of false memories. Some evidence for this assumption has already been described, in that MTL damage causes autobiographical amnesia and reduces the DRM illusion, whereas PFC damage sometimes causes autobiographical confabulations and elevates the DRM illusion. Other evidence has focused on individual differences in neurologically intact subjects. Individual differences in the propensity for both DRM and autobiographical false memories are not necessary for one phenomenon to be relevant to the other, but the existence of such individual differences is sufficient to establish a link. ${ }^{4}$

An individual differences approach to generalizability assumes that (1) some processes are common to all kinds of false memories and (2) people can reliably vary in these processes and, hence, in their propensity for false memories. In support of these assumptions, positive (albeit modest) correlations have been reported between the DRM illusion and false memories in other laboratory tasks, including false memories for words and pictures (Lövdén, 2003; but see Salthouse \& Siedlecki, 2007) and acceptance of misleading information about previous ex- 
periences (Eisen, Cardenas, Kistorian, Yu, \& Tirtibudi, 1999). Also, Blair, Lenton, and Hastie (2002) found stable individual differences in the DRM illusion across testing times, demonstrating test-retest reliability. If the processes that cause lab-based false memories also apply outside the lab, some people should be more prone to both laboratory and autobiographical false memories.

Platt, Lacey, Iobst, and Finkelman (1998) were the first to report a relationship between DRM false memories and autobiographical memory accuracy. Undergraduates were contacted the night of a widely viewed public event (the O. J. Simpson trial) and reported details about their hearing of the verdict (e.g., location, activity, informant). Several months later, these individuals were asked to report these same details, and the consistency across the two reports was scored. Importantly, some of the inconsistent retellings were made with high confidence, demonstrating autobiographical memory distortion. Platt et al. found a significant negative correlation between autobiographical memory accuracy and DRM false recall of related lures $(r=-.30, p<.05)$ and a marginally significant correlation with DRM false recognition $(r=-.23, p=$ $.05)$. Thus, the subjects with less reliable autobiographical memories were more prone to DRM false memories.

Two studies by McNally and colleagues provide additional evidence that the DRM illusion is related to autobiographical memories that, if not definitively false, are sufficiently fantastic to be assumed false by many skeptics. Clancy, McNally, Schacter, Lenzenweger, and Pitman (2002) recruited people with memories of space alien abduction. The sincerity of these reports was verified by interview and gains additional credibility from physiological responses in a different sample (McNally et al., 2004). Clancy et al. (2002) found that the abductees were more prone to DRM false recall $(M=.29)$ than a control group matched on age and education $(M=.14)$, and similarly for false recognition ( $M=.67$ and .42 , respectively). The groups did not differ on true memory of the actual studied words. A group of individuals who believed that they had been abducted by aliens but had no specific memories of the event were also more prone to DRM false memories, but some analyses suggested that the relationship was stronger for those who reported actual memories. French, Santomauro, Hamilton, Fox, and Thalbourne (2008) also found that people reporting extraterrestrial experiences were more prone to DRM false recognition (experiencers, $M=.59$; controls, $M=.49$ ), but this difference was not significant, potentially because their sample included people who reported a U.F.O. sighting without a memory of abduction.

A more recent study by Meyersburg, Bogdan, Gallo, and McNally (2009) provided a conceptual replication and extension of the Clancy et al. (2002) study (Figure 3). They found that individuals reporting specific memories from past lives (e.g., selling newspapers in the 1800s) were more susceptible to DRM false recall $(M=.44)$ than controls matched for age and education $(M=.30)$, and similarly for false recognition $(M=.76$ and .48 , respectively). As in Clancy et al. (2002), the groups did not differ

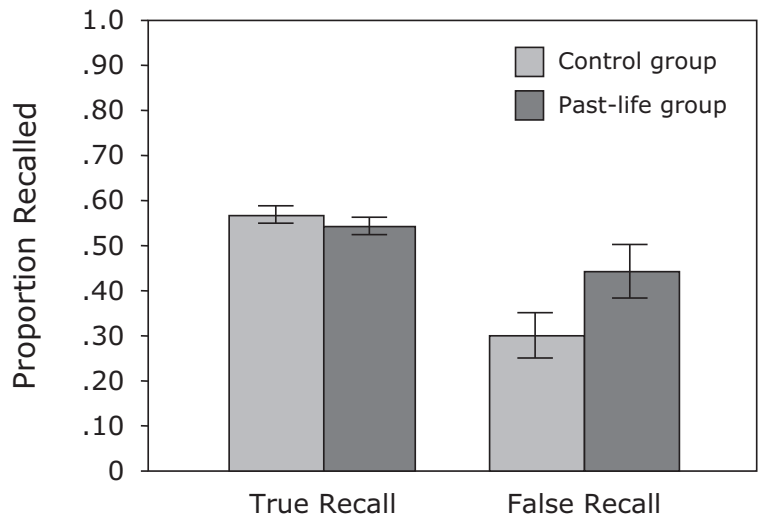

Figure 3. Elevated DRM illusion in people with memories of past lives, indicating continuity between the lab and life. The data are from "False Memory Propensity in People Reporting Recovered Memories of Past Lives," by C. A. Meyersburg, R. Bogdan, D.A. Gallo, and R. J. MeNally, 2009, Journal of Abnormal Psychology, 118, pp. 399-404. Copyright 2009 by the American Psychological Association. Reprinted with permission.

in true memory of studied words. Note that the recall testing may have influenced this recognition test (as in Clancy et al., 2002; French et al., 2008; and Platt et al., 1998), but a marginally significant false recognition difference was found on an independent recognition test (past life group, $M=.52$; controls, $M=.42$; one-tailed $p=.069$ ). The finding that recognition effects were greater when they were preceded by prior recall potentially implicates a retrieval monitoring difficulty.

Three studies of recovered memories also provide a link between the DRM illusion and autobiographical memory. These studies tested adult subjects who claimed to have recovered previously repressed memories of childhood abuse. In each of these studies, it was found that the recovered memory group was more susceptible to the DRM illusion than individuals with continuous memories of abuse or individuals who did not report any abuse (Clancy, Schacter, McNally, \& Pitman, 2000; Geraerts et al., 2009; Geraerts, Smeets, Jelicic, van Heerden, \& Merckelbach, 2005). Of course, the veracity of recovered memories is controversial. Some recovered memories may be false, others may reflect true memories that were temporarily forgotten or repressed, and still others may reflect a distorted reinterpretation of actual events that were never repressed or forgotten (see McNally \& Geraerts, 2009; Schooler, Bendiksen, \& Ambadar, 1997). The point to be made here is that, by any of these interpretations, the recovered memory experience reflects some type of autobiographical memory error (i.e., either temporary forgetting or some sort of distortion). As such, these studies further demonstrate a link between naturally occurring autobiographical memory errors and the DRM illusion.

In contrast to these more naturally occurring autobiographical memory phenomena, the two DRM studies on lab-induced autobiographical distortions were inconclusive. Wilkinson and Hyman (1998) found no relationship 
between the DRM illusion and the influence of mental elaboration on mistaken claims of "remembering" a childhood event (on a scale of $1-7 ; 1=$ know, $7=$ remember). The mean autobiographical rating was only $2.36(S D=$ 1.37), however, suggesting that relatively few false autobiographical memories were created. Qin, Ogle, and Goodman (2008) used a variant of the lost-in-the-mall technique (e.g., Loftus \& Pickrell, 1995), in which subjects repeatedly tried to remember a false childhood event. Performance on this task was related to measures of response bias and unrelated lure recall but not to the DRM illusion (i.e., false memories of related lures). However, as in Wilkinson and Hyman, the levels of induced false autobiographical memories were relatively low, with most of them within the no memory but trying range (i.e., 2 on a 4-point scale). Additional studies are needed that induce false autobiographical memories with more than a few items or questions, thereby increasing psychometric reliability.

To summarize, the results of the seven studies investigating naturally occurring autobiographical memory phenomena were very consistent, but the two studies labinduced autobiographical errors were inconclusive. With respect to the former, three studies found a significant positive relationship between the DRM illusion and false (or at least fantastic) autobiographical memories (Clancy et al., 2002; Meyersburg et al., 2009; Platt et al., 1998). The one exception included a more questionable sample, and even here, the DRM data were in the predicted direction (French et al., 2008). Three other studies found a significant positive relationship between the DRM illusion and the recovered memory phenomenon (Clancy et al., 2000; Geraerts et al., 2009; Geraerts et al., 2005). Considered as a whole, these studies indicate a significant link between the DRM illusion and autobiographical memory phenomena that have been associated with errors and distortion. These findings argue against the suggestion that the DRM illusion is unrelated to false autobiographical memories (e.g., DePrince et al., 2004; Freyd \& Gleaves, 1996). However, these results are mostly correlational, leaving open the question as to what aspects of the DRM illusion might apply to false autobiographical memories. Some researchers have begun to address this question, but as is described in the next section, there is still much to learn.

\section{Closure: What We Do Not Know About the Problem}

Despite the evidence that the DRM illusion is related to naturally occurring false autobiographical memories, exactly why this relationship exists is poorly understood. Researchers investigating individual differences often appeal to source monitoring (e.g., Meyersburg et al., 2009; Qin et al., 2008), but general appeals to source monitoring are only the first step. According to the source-monitoring framework, all false memories reflect a breakdown of source monitoring (e.g., Johnson, 2006). A deeper understanding requires an unpacking of the activation and monitoring processes that might drive individual differences in false memories.

Figure 4 illustrates an elaboration of the activation/ monitoring framework that applies to all false memories. Activation is broadly divided into top-down and bottomup processes. Top-down processes actively elaborate or go beyond the given information, usually in an effort to comprehend it. Such processes include the mental generation of associations and gist in the DRM task, as well as information-processing heuristics contributing to other kinds of false memories (e.g., inferences, schemas). Bottom-up activation results from imperfect encoding and retrieval, which can occur even in the absence of top-down elaborations. Such processes include the failure to accurately associate or bind together the details of an event, leading to partial recollections, or the retrieval of representations that contain overlapping and confusable features. Many source memory errors involve

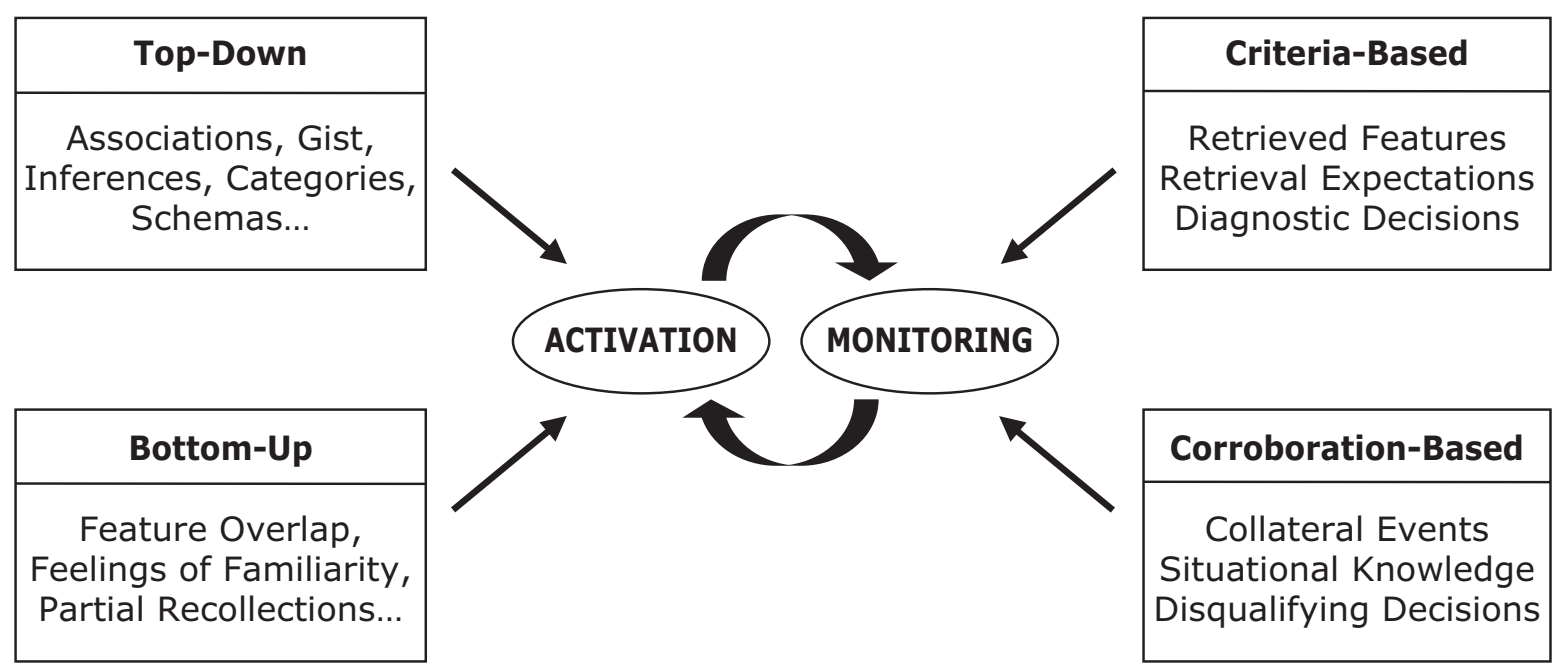

Figure 4. An activation/monitoring framework for the constructive processes involved in false memories. 
such bottom-up failures, as when imagined events are confused with real ones, or when misinformation is confused with what was witnessed. Familiarity can also be considered a bottom-up process, to the extent that it arises from stimulus properties requiring little elaboration. As was discussed previously, partial recollections and imagery may also be involved in DRM illusory recollections, indicating that top-down and bottom-up processes interact in creating false memories.

Multiple activation processes should also be involved in false autobiographical memories. For example, consider the possibility that some memories of space alien abductions are false. In these instances, the illusory content is thought to originate from fragmented images and sensations occurring during sleep abnormalities (a bottom-up process), as well as the elaboration of this information with cultural scripts derived from science fiction and other sources (a top-down process; see Clancy et al., 2002). There are different types of activation that arise for different functional reasons. To understand different kinds of false memories, one needs to identify the specific types of information that create the contents of the illusory recollection and how and why they are activated.

Monitoring is broadly divided into criteria-based and corroboration-based processes. Criteria-based monitoring involves diagnostic decisions, whereas corroborationbased monitoring involves disqualifying decisions. As was reviewed above, there is evidence for each of these processes in the DRM task and other lab tasks, but these decision processes should also apply to autobiographical memories. For example, false memories of space alien abduction can be avoided using either a diagnostic decision (e.g., "I wasn't abducted by space aliens last night, because I would have a distinctive recollection of that") or a disqualifying decision (e.g., "I wasn't abducted by space aliens last night, because I remember watching movies all night instead"). Of course, these memories are usually rejected on the basis of beliefs of plausibility or credibility, but even here the logic of the decision process can be considered disqualifying (e.g., "I wasn't abducted by space aliens last night, because I do not believe in the existence of space aliens"). In contrast, false memories of space alien abduction may persist if one's beliefs invalidate the logic of these decision processes (e.g., the memory is not expected to be distinctive because of alien mind-altering technology, the usual rules of corroborating events do not apply because of alien time-warping technology, and plausibility is irrelevant because aliens do exist).

Broadening the activation/monitoring framework helps to conceptualize additional individual differences that are relevant to both the DRM illusion and false autobiographical memories. Consider dissociation as it is measured by the Dissociative Experiences Scale (DES; E. M. Bernstein \& Putnam, 1986). Dissociation reflects disruptions in everyday conscious experiences (e.g., feeling that familiar people or places are unfamiliar or unreal, experiencing daydreams as reality) and may reflect a failure to successfully use monitoring processes or the use of lax criteria to interpret ongoing experiences (Johnson, 2006). Relevant to this idea, several researchers have reported a positive link between the DRM illusion and DES scores (e.g., Clancy et al., 2002; Clancy et al., 2000; Wilkinson \& Hyman, 1998; Winograd, Peluso, \& Glover, 1998; Zoellner, Foa, Brigidi, \& Przeworski, 2000; see also Laws \& Bhatt, 2005), although this link is not always found (e.g., Bremner, Shobe, \& Kihlstrom, 2000; Geraerts et al., 2005; Platt et al., 1998; Wright, Startup, \& Mathews, 2005). Dehon, Bastin, and Laroi (2008) recently replicated the positive relationship between the DRM illusion and DES scores. More importantly, they modified the typical DRM task to separately estimate activation and monitoring processes (cf. Brédart, 2000), and they found that the relationship between the DRM task and DES scores was specific to the monitoring component $(r=.28, p<.001)$.

The idea that dissociative experiences are related to monitoring also explains why dissociative experiences correlate positively with other false-memory tasks (for reviews, see Eisen \& Lynn, 2001; Giesbrecht, Lynn, Lilienfeld, \& Merckelbach, 2008). These tasks include susceptibility to misleading questions about experienced events (e.g., Eisen \& Carlson, 1998; Hekkanen \& McEvoy, 2002), as well as suggestive techniques to manipulate false autobiographical beliefs (e.g., Hyman \& Billings, 1998; Porter, Birt, Yuille, \& Lehman, 2000). False information is activated in these tasks through processes that are likely to differ from the DRM task, but the tasks may tap a common set of monitoring processes. Similarly, people who believe that they have recovered memories or have lived past lives are more susceptible to memory errors on tasks other than the DRM illusion, again implicating monitoring processes (McNally, Clancy, Barrett, \& Parker, 2005; Peters, Horselenberg, Jelicic, \& Merckelbach, 2007).

Research on working memory is also consistent with a monitoring explanation of individual differences in false memories. Working memory involves the active maintenance and manipulation of information and recruits dorsolateral prefrontal regions (Curtis \& D'Esposito, 2003), the same regions that are involved in retrieval monitoring in the DRM task and other tasks. Lövdén (2003) found that individual differences in working memory correlated negatively with the DRM illusion and other false-memory tasks (see also Parker, Garry, Engle, Harper, \& Clifasefi, 2008; Peters, Jelicic, Haas, \& Merckelbach, 2006; Peters, Jelicic, Verbeek, \& Merckelbach, 2007; Peters, Smeets, Giesbrecht, Jelicic, \& Merckelbach, 2007). Moreover, the relationship between working memory and the DRM illusion can be stronger under conditions that require a high degree of monitoring (McCabe \& Smith, 2002; Watson, Bunting, Poole, \& Conway, 2005), and Unsworth and Brewer (2010) used latent variable analysis to show that source monitoring mediates the relationship between working memory and DRM false memory. As with the DES findings, these findings add weight to the idea that different false-memory tasks tap a common set of monitoring processes.

The activation/monitoring perspective also highlights what we still do not know. The results of the previous stud- 
ies implicate monitoring as an important construct, but what types of monitoring might differ across individuals and situations? Also, can individual differences in activation processes explain some of the effects? Graham (2007) found that individuals high in need-for-cognition were more susceptible to the DRM illusion, even though they should have been more likely to use monitoring processes. These people may have used more elaborate semantic processes at study, thereby enhancing activation. Similar effects may be involved in some of the people that hold fantastic autobiographical memories. These individuals may have more vivid imaginations and creative associative processes that enhance different kinds of activation.

Another unanswered question is whether these individual differences are due to motivational factors or whether they are due to genuine limits in the ability to engage monitoring and/or constrain activation. If they are due to ability, can they be attributed to different neuroanatomical phenotypes? In a diffusion tensor imaging study, Fuentemilla et al. (2009) found that individual differences in the DRM illusion were positively related to fractional anisotropy scores (thought to reflect the efficiency of neuronal connections) in the superior longitudinal fascicle, which connects prefrontal regions to more posterior ones. Because the relationship was positive, it was attributed to increased activation of related lures, but more work along these lines is needed. If a task designed to isolate monitoring processes were used, a negative relationship might have been found between connectivity measures and false memories.

\section{Judgment: Problems and Possibilities}

Three conclusions can be made from this review. First, the DRM illusion is a basic type of false memory that has had a large impact on the field. Second, an interacting set of activation and monitoring processes influence these false memories. Nuances of these processes are still being researched and debated, but it is clear that they are cognitively dissociable and they are related to different underlying neural processes. Third, individual differences in the DRM illusion are related to false autobiographical memories, but the exact reasons are still unclear.

Should researchers continue to use the DRM task to study false memories? The answer depends on one's ultimate research goals. The DRM task is a useful way to study false memories, and we know at least as much about these kinds of false memories as we do about any other kind. If one's goal is to study false memories as a phenomenon, the DRM task will continue to be fruitful. If one's goal instead is to isolate the different processes that contribute to false memories, then the original DRM task may be less ideal. If the past 15 years have taught us anything, it is that multiple processes drive even the most basic false memories.

The contribution of multiple activation and monitoring processes in the DRM task can cause interpretative ambiguities. Some ambiguities were discussed in the context of neuroimaging, developmental, and individual differences studies, but they also exist with respect to experimentally manipulated variables. Consider the influence of sleep. In several experiments, Fenn, Gallo, Margoliash, Roediger, and Nusbaum (2009) found that sleep decreased the DRM illusion, potentially by enhancing some kind of monitoring. In several other experiments, Payne et al. (2009) found that sleep increased the DRM illusion, potentially by enhancing some kind of activation. These studies were well designed, suggesting that these discrepancies are real and potentially due to the relative contribution of activation and monitoring processes across different (and somewhat arbitrary) versions of the DRM task (see Diekelmann, Born, \& Wagner, 2010). These were the first studies to investigate sleep and false memories, so using the DRM illusion seems appropriate. However, different methods are now needed to isolate the effects of sleep on component processes.

One solution is to modify the DRM task to better constrain the contributing processes. Incidental encoding tasks could minimize study-phase monitoring. Warnings to avoid the illusion just before test could minimize strategic guessing or liberal response bias, helping to isolate false-memory effects. More consistent use of fine-grained subjective judgments would also help. To measure activation, one could add an implicit test or a gist-memory test, whereas to measure monitoring, subjective reports could be obtained or modeling procedures could be used. Some of these techniques have already been used, as in studies investigating the effects of emotion on false memories (Brainerd, Stein, Silveira, Rohenkohl, \& Reyna, 2008; Palmer \& Dodson, 2009), but much more still needs to be done.

Another solution is to use memory tasks that more precisely identify the specific process of interest. For example, recollection-based exclusion tasks are a useful way to isolate disqualifying monitoring processes (e.g., Jacoby, 1991), whereas the criterial recollection task is a useful way to isolate diagnostic monitoring processes (e.g., Gallo et al., 2004). Work with this latter task has replicated some DRM effects but also indicates that the activation component of the DRM task can mask important monitoring effects (Gallo, Meadow, Johnson, \& Foster, 2008). No task is process pure, but some tasks are better at measuring specific processes because they were specifically designed to do so.

After 15 years of research, it is clear that the DRM illusion has contributed a great deal to our understanding of false memories. This research area exemplifies how cognitive psychology can integrate basic and applied questions using multiple levels of analysis. The individual differences findings are a prime example, because they reveal an important continuity from the lab to life that is beginning to be understood at a neurocognitive level. Nevertheless, there is still much to discover about the specific processes that cause these individual differences, and the DRM task cannot tackle this problem alone. False memories are complex phenomena involving multiple and often competing processes. Future attempts to understand the specific processes that drive individual differences in false memories need to use tasks designed to isolate these 
processes. A more process-driven approach is critical if the goal is to understand the causes of false memories that generalize across tasks and situations. A deeper consideration of the functional problems that these processes aim to solve, or the nonlaboratory situations in which they are typically used, will also illuminate the relationship between different kinds of false memories. It might even reveal new kinds of false memories altogether.

\section{AUTHOR NOTE}

Special thanks go to Charles Brainerd, John Kihlstrom, Henry Roediger, and the University of Chicago Memory Lab for helpful comments on an earlier draft. Correspondence concerning this article should be addressed to D. A. Gallo, Department of Psychology, Center of Cognitive and Social Neuroscience, University of Chicago, $5848 \mathrm{~S}$. University Avenue, Chicago, IL 60637 (e-mail: dgallo@uchicago.edu).

\section{REFERENCES}

Abe, N., Okuda, J., Suzuki, M., Sasaki, H., Matsuda, T., Mori, E., ET AL. (2008). Neural correlates of true memory, false memory, and deception. Cerebral Cortex, 18, 2811-2819.

Anaki, D., Faran, Y., Ben-Shalom, D., \& Henik, A. (2005). The false memory and the mirror effects: The role of familiarity and backward association in creating false recollections. Journal of Memory \& Language, 52, 87-102.

Anastasi, J. S., Rhodes, M. G., Marquez, S., \& Velino, V. (2005). The incidence of false memories in native and nonnative speakers. Memory, 13, 815-828.

ARNDT, J. (2006). Distinctive information and false recognition: The contribution of encoding and retrieval factors. Journal of Memory \& Language, 54, 113-130.

ARndt, J., \& Hirshman, E. (1998). True and false recognition in MINERVA2: Explanations from a global matching perspective. Journal of Memory \& Language, 39, 371-391.

ARNDT, J., \& REDER, L. M. (2003). The effect of distinctive visual information on false recognition. Journal of Memory \& Language, 48 $1-15$

Balota, D. A., Cortese, M. J., Duchek, J. M., Adams, D., Roediger, H. L., III, McDermott, K. B., \& Yerys, B. E. (1999). Veridical and false memories in healthy older adults and in dementia of the Alzheimer's type. Cognitive Neuropsychology, 16, 361-384.

BANAJI, M. R., \& CROWDER, R. G. (1989). The bankruptcy of everyday memory. American Psychologist, 44, 1185-1193.

BANKS, W. P. (2000). Recognition and source memory as a multivariate decision process. Psychological Science, 11, 267-273.

Bartlett, F. C. (1932). Remembering: A study in experimental and social psychology. Cambridge: Cambridge University Press.

BäUmL, K.-H., \& KuhbandNER, C. (2003). Retrieval-induced forgetting and part-list cuing in associatively structured lists. Memory \& Cognition, 31, 1188-1197.

BenJamin, A. S. (2001). On the dual effects of repetition on false recognition. Journal of Experimental Psychology: Learning, Memory, \& Cognition, 27, 941-947.

Bernstein, D. M., \& Loftus, E. F. (2009). How to tell if a particular memory is true or false. Perspectives on Psychological Science, 4, 370-374.

Bernstein, E. M., \& Putnam, F. W. (1986). Development, reliability, and validity of a dissociation scale. Journal of Nervous \& Mental Disease, 174, 727-735.

Blair, I. V., Lenton, A. P., \& Hastie, R. (2002). The reliability of the DRM paradigm as a measure of individual differences in false memories. Psychonomic Bulletin \& Review, 9, 590-596.

BRAINERD, C. J., \& REYNA, V. F. (1998). When things that were never experienced are easier to "remember" than things that were. Psychological Science, 9, 484-489.

BRAinerd, C. J., \& Reyna, V. F. (2005). The science of false memory. Oxford: Oxford University Press.

Brainerd, C. J., Reyna, V. F., \& CeCI, S. J. (2008). Developmental reversals in false memory: A review of data and theory. Psychological Bulletin, 134, 343-382.
Brainerd, C. J., Reyna, V. F., \& Forrest, T. J. (2002). Are young children susceptible to the false-memory illusion? Child Development, 73, 1363-1377.

Brainerd, C. J., Reyna, V. F., Wright, R., \& Mojardin, A. H. (2003). Recollection rejection: False-memory editing in children and adults. Psychological Review, 110, 762-784.

Brainerd, C. J., Stein, L. M., Silveira, R. A., Rohenkohl, G., \& REYNA, V. F. (2008). How does negative emotion cause false memories? Psychological Science, 19, 919-925.

Brainerd, C. J., Wright, R., Reyna, V. F., \& Mojardin, A. H. (2001). Conjoint recognition and phantom recollection. Journal of Experimental Psychology: Learning, Memory, \& Cognition, 27, 307-327.

Brainerd, C. J., Yang, Y., Reyna, V. F., Howe, M. L., \& Mills, B. A. (2008). Semantic processing in "associative" false memory. Psychonomic Bulletin \& Review, 15, 1035-1053.

BRÉDART, S. (2000). When false memories do not occur: Not thinking of the lure or remembering that it was not heard? Memory, 8, 123-128.

Bremner, J. D., Shobe, K. K., \& Kinlstrom, J. F. (2000). False memories in women with self-reported childhood sexual abuse: An empirical study. Psychological Science, 11, 333-337.

BREWER, W. F. (1977). Memory for the pragmatic implications of sentences. Memory \& Cognition, 5, 673-678.

Brown, J., LewIS, V. J., \& MonK, A. F. (1977). Memorability, word frequency, and negative recognition. Quarterly Journal of Experimental Psychology, 29, 461-473.

Bruce, D., \& Winograd, E. (1998). Remembering Deese's 1959 articles: The Zeitgeist, the sociology of science, and false memories. Psychonomic Bulletin \& Review, 5, 615-624.

Buchanan, L., Brown, N. R., Cabeza, R., \& Maitson, C. (1999). False memories and semantic lexicon arrangement. Brain \& Language, 68, 172-177.

Buchner, A., ERdfelder, E., \& VAterrodt-PlünNEcke, B. (1995). Toward unbiased measurement of conscious and unconscious memory processes within the process dissociation framework. Journal of Experimental Psychology: General, 124, 137-160.

Budson, A. E., Daffner, K. R., Desikan, R., \& Schacter, D. L. (2000). When false recognition is unopposed by true recognition: Gist-based memory distortion in Alzheimer's disease. Neuropsychology, 14, 277-287.

Budson, A. E., Desikan, R., Daffner, K. R., \& Schacter, D. L. (2001). Perceptual false recognition in Alzheimer's disease. Neuropsychology, 15, 230-243.

Budson, A. E., Sullivan, A. L., Mayer, E., Daffner, K. R., Black, P. M., \& Schacter, D. L. (2002). Suppression of false recognition in Alzheimer's disease and in patients with frontal lobe lesions. Brain, 125, 2750-2765.

BuRnham, W. H. (1889). Memory, historically and experimentally considered: III. Paramnesia. American Journal of Psychology, 2, 431-464.

Butler, K. M., McDaniel, M. A., Dornburg, C. C., Price, A. L., \& RoEDIger, H. L., III (2004). Age differences in veridical and false recall are not inevitable: The role of frontal lobe function. Psychonomic Bulletin \& Review, 11, 921-925.

Cabeza, R., Rao, S. M., Wagner, A. D., Mayer, A. R., \& Schacter, D. L. (2001). Can medial temporal lobe regions distinguish true from false? An event-related functional MRI study of veridical and illusory recognition memory. Proceedings of the National Academy of Sciences, 98, 4805-4810.

Carneiro, P., \& Fernandez, A. (2010). Age differences in the rejection of false memories: The effects of giving warning instructions and slowing the presentation rate. Journal of Experimental Child Psychology, 105, 81-97.

Carneiro, P., Fernandez, A., \& Dias, A. R. (2009). The influence of theme identifiability on false memories: Evidence for age-dependent opposite effects. Memory \& Cognition, 37, 115-129.

Castel, A. D., McCabe, D. P., Roediger, H. L., III, \& Heitman, J. L. (2007). The dark side of expertise: Domain-specific memory errors. Psychological Science, 18, 3-5.

Ciaramelli, E., Ghetti, S., \& Borsotti, M. (2009). Divided attention during retrieval suppresses false recognition in confabulation. Cortex, 45, 141-153.

Clancy, S. A., McNally, R. J., Schacter, D. L., Lenzenweger, M. F., \& Pitman, R. K. (2002). Memory distortion in people reporting abduction by aliens. Journal of Abnormal Psychology, 111, 455-461. 
Clancy, S. A., Schacter, D. L., McNally, R. J., \& Pitman, R. K. (2000). False recognition in women reporting recovered memories of sexual abuse. Psychological Science, 11, 26-31.

Cotel, S. C., Gallo, D. A., \& Seamon, J. G. (2008). Evidence that nonconscious processes are sufficient to produce false memories. Consciousness \& Cognition, 17, 210-218.

Curtis, C. E., \& D'Esposito, M. (2003). Persistent activity in the prefrontal cortex during working memory. Trends in Cognitive Sciences, 7, 415-423

DEESE, J. (1959). On the prediction of occurrence of particular verbal intrusions in immediate recall. Journal of Experimental Psychology, $\mathbf{5 8}, 17-22$

Dehon, H., Bastin, C., \& Laroi, F. (2008). The influence of delusional ideation and dissociative experiences on the resistance to false memories in normal healthy subjects. Personality \& Individual Differences, 45, 62-67.

DePrince, A., Allard, C. B., OH, H., \& Freyd, J. J. (2004). What's in a name for memory errors? Implications and ethical issues arising from the use of the term "false memory" for errors in memory for details. Ethics \& Behavior, 14, 201-233.

Dewhurst, S. A., Barry, C., Swannell, E. R., Holmes, S. J., \& Bathurst, G. L. (2007). The effect of divided attention on false memory depends on how memory is tested. Memory \& Cognition, 35, 660-667.

Diekelmann, S., Born, J., \& Wagner, U. (2010). Sleep enhances false memories depending on general memory performance. Behavioural Brain Research, 208, 425-429.

DodD, M. D., \& MACLEOD, C. M. (2004). False recognition without intentional learning. Psychonomic Bulletin \& Review, 11, 137-142.

Dodhia, R. M., \& Metcalfe, J. (1999). False memories and source monitoring. Cognitive Neuropsychology, 16, 489-508.

Dodson, C. S., \& Hege, A. C. G. (2005). Speeded retrieval abolishes the false-memory suppression effect: Evidence for the distinctiveness heuristic. Psychonomic Bulletin \& Review, 12, 726-731.

Dodson, C. S., \& Schacter, D. L. (2001). "If I had said it I would have remembered it": Reducing false memories with a distinctiveness heuristic. Psychonomic Bulletin \& Review, 8, 155-161.

Dodson, C. S., \& Schacter, D. L. (2002). When false recognition meets metacognition: The distinctiveness heuristic. Journal of Memory \& Language, 46, 782-803.

Eisen, M. L., Cardenas, E., Kistorian, V., Yu, A. S., \& Tirtibudi, P. (1999, July). Individual differences in college students' resistance to misleading information. Paper presented at the third biennial meeting of the Society for Applied Research in Memory and Cognition, University of Colorado, Boulder.

EISEN, M. L., \& CARLSON, E. B. (1998). Individual differences in suggestibility: Examining the influence of dissociation, absorption, and a history of childhood abuse. Applied Cognitive Psychology, 12, 47-61.

Eisen, M. L., \& LyNN, S. J. (2001). Dissociation, memory and suggestibility in adults and children. Applied Cognitive Psychology, 15, S49-S73.

Fabiani, M., Stadler, M. A., \& Wessels, P. M. (2000). True but not false memories produce a sensory signature in human lateralized brain potentials. Journal of Cognitive Neuroscience, 12, 941-949.

Fenn, K. M., Gallo, D. A., Margoliash, D., Roediger, H. L., III, \& Nusbaum, H. C. (2009). Reduced false memory after sleep. Learning \& Memory, 16, 509-513.

French, C. C., Santomauro, J., Hamilton, V., Fox, R., \& ThalBourne, M. A. (2008). Psychological aspects of the alien contact experience. Cortex, 44, 1387-1395.

FREYD, J. J., \& GleAVES, D. H. (1996). "Remembering" words not presented in lists: Relevance to the current recovered/false memory controversy. Journal of Experimental Psychology: Learning, Memory, \& Cognition, 22, 811-813.

Fuentemilla, L., Càmara, E., Münte, T. F., Krämer, U. M., CuniLleRA, T., MARCo-PALlarés, J., ET AL. (2009). Individual differences in true and false memory retrieval are related to white matter brain microstructure. Journal of Neuroscience, 29, 8698-8703.

Gallate, J., Chi, R., Ellwood, S., \& Snyder, A. (2009). Reducing false memories by magnetic pulse stimulation. Neuroscience Letters, 449, 151-154.

GALLO, D. A. (2004). Using recall to reduce false recognition: Diagnos- tic and disqualifying monitoring. Journal of Experimental Psychology: Learning, Memory, \& Cognition, 30, 120-128.

Gallo, D. A. (2006). Associative illusions of memory: False memory research in DRM and related tasks. New York: Psychology Press.

Gallo, D. A., Bell, D. M., Beier, J. S., \& Schacter, D. L. (2006). Two types of recollection-based monitoring in younger and older adults: Recall-to-reject and the distinctiveness heuristic. Memory, 14, 730741.

Gallo, D. A., Cotel, S. C., Moore, C. D., \& Schacter, D. L. (2007). Aging can spare recollection-based retrieval monitoring: The importance of event distinctiveness. Psychology \& Aging, 22, 209-213

Gallo, D. A., Kensinger, E. A., \& Schacter, D. L. (2006). Prefrontal activity and diagnostic monitoring of memory retrieval: fMRI of the criterial recollection task. Journal of Cognitive Neuroscience, $\mathbf{1 8}$, $135-148$.

Gallo, D. A., McDonough, I. M., \& Scimeca, J. (2010). Dissociating source memory decisions in the prefrontal cortex: fMRI of diagnostic and disqualifying monitoring. Journal of Cognitive Neuroscience, 22, 955-969.

Gallo, D. A., Meadow, N. G., Johnson, E. L., \& Foster, K. T. (2008). Deep levels of processing elicit a distinctiveness heuristic: Evidence from the criterial recollection task. Journal of Memory \& Language, 58, 1095-1111.

Gallo, D. A., Roberts, M. J., \& Seamon, J. G. (1997). Remembering words not presented in lists: Can we avoid creating false memories? Psychonomic Bulletin \& Review, 4, 271-276.

Gallo, D. A., \& Roediger, H. L., III (2003). The effects of associations and aging on illusory recollection. Memory \& Cognition, $\mathbf{3 1}$, 1036-1044.

Gallo, D. A., Roediger, H. L., III, \& McDermott, K. B. (2001). Associative false recognition occurs without strategic criterion shifts Psychonomic Bulletin \& Review, 8, 579-586.

Gallo, D. A., Weiss, J. A., \& Schacter, D. L. (2004). Reducing false recognition with criterial recollection tests: Distinctiveness heuristic versus criterion shifts. Journal of Memory \& Language, 51, 473-493.

Geraci, L., \& McCABE, D. P. (2006). Examining the basis for illusory recollection: The role of remember/know instructions. Psychonomic Bulletin \& Review, 13, 466-473.

Geraerts, E., Lindsay, D. S., Merckelbach, H., Jelicic, M., Raymaekers, L., Arnold, M. M., \& Schooler, J. W. (2009). Cognitive mechanisms underlying recovered-memory experiences of childhood sexual abuse. Psychological Science, 20, 92-98.

Geraerts, E., Smeets, E., Jelicic, M., van Heerden, J., \& MerckelBACH, H. (2005). Fantasy proneness, but not self-reported trauma is related to DRM performance of women reporting recovered memories of childhood sexual abuse. Consciousness \& Cognition, 14, 602-612.

GHETTI, S. (2003). Memory for nonoccurrences: The role of metacognition. Journal of Memory \& Language, 48, 722-739.

Ghetti, S. (2008). Processes underlying developmental reversals in false-memory formation: Comment on Brainerd, Reyna, and Ceci (2008). Psychological Bulletin, 134, 764-767.

Giesbrecht, T., Lynn, S. J., Lilienfeld, S. O., \& Merckelbach, H. (2008). Cognitive processes in dissociation: An analysis of core theoretical assumptions. Psychological Bulletin, 134, 617-647.

Gleaves, D. H., Smith, S. M., Butler, L. D., \& Spiegel, D. (2004). False and recovered memories in the laboratory and clinic: A review of experimental and clinical evidence. Clinical Psychology: Science \& Practice, 11, 3-28.

Graham, L. M. (2007). Need for cognition and false memory in the Deese-Roediger-McDermott paradigm. Personality \& Individual Differences, 42, 409-418.

Grierson, B. (2003, July 27). A bad trip down memory lane. New York Times Magazine, p. 36.

Gunter, R. W., Bodner, G. E., \& Azad, T. (2007). Generation and mnemonic encoding induce a mirror effect in the DRM paradigm. Memory \& Cognition, 35, 1083-1092.

Gunter, R. W., Ivanko, S. L., \& Bodner, G. E. (2005). Can test list context manipulations improve recognition accuracy in the DRM paradigm? Memory, 13, 862-873.

Hasson, U., Nusbaum, H. C., \& Small, S. L. (2007). Brain networks subserving the extraction of sentence information and its encoding to memory. Cerebral Cortex, 17, 2899-2913. 
Hautus, M. J., Macmillan, N. A., \& Rotello, C. M. (2008). Toward a complete decision model of item and source recognition. Psychonomic Bulletin \& Review, 15, 889-905.

Hege, A. C. G., \& Dodson, C. S. (2004). Why distinctive information reduces false memories: Evidence for both impoverished relationalencoding and distinctiveness heuristic accounts. Journal of Experimental Psychology: Learning, Memory, \& Cognition, 30, 787-795.

Hekranen, S., \& McEvoy, C. (2002). False memories and sourcemonitoring problems: Criterion differences. Applied Cognitive Psychology, 16, 73-85.

Hicks, J. L., \& Starns, J. J. (2006). The roles of associative strength and source memorability in the contextualization of false memory. Journal of Memory \& Language, 54, 39-53.

Hintzman, D. L., \& Curran, T. (1994). Retrieval dynamics of recognition and frequency judgments: Evidence for separate processes of familiarity and recall. Journal of Memory \& Language, 33, 1-18.

Howe, M. L. (2008). What is false memory development the development of? Comment on Brainerd, Reyna, and Ceci (2008). Psychological Bulletin, 134, 768-772.

Howe, M. L., Wimmer, M. C., Gagnon, N., \& Plumpton, S. (2009). An associative-activation theory of children's and adult's memory illusions. Journal of Memory \& Language, 60, 229-251.

Hutchison, K. A., \& Balota, D. A. (2005). Decoupling semantic and associative information in false memories: Explorations with semantically ambiguous and unambiguous critical lures. Journal of Memory \& Language, 52, 1-28.

Hyman, I. E., JR., \& Billings, F. J. (1998). Individual differences and the creation of false childhood memories. Memory, 6, 1-20.

Hyman, I. E., JR., \& LofTus, E. F. (2002). False childhood memories and eyewitness memory errors. In M. L. Eisen, J. A. Quas, \& G. S. Goodman (Eds.), Memory and suggestibility in the forensic interview (pp. 63-84). Mahwah, NJ: Erlbaum.

JACOBY, L. L. (1991). A process dissociation framework: Separating automatic from intentional uses of memory. Journal of Memory \& Language, 30, 513-541.

JACOBY, L. L. (1998). Invariance in automatic influences of memory: Toward a user's guide for the process-dissociation procedure. Journal of Experimental Psychology: Learning, Memory, \& Cognition, 24, 3-26.

Jacoby, L. L., Kelley, C. M., \& Dywan, J. (1989). Memory attributions. In H. L. Roediger III \& F. I. M. Craik (Eds.), Varieties of memory and consciousness: Essays in honour of Endel Tulving (pp. 391-422). Hillsdale, NJ: Erlbaum.

Johnson, M. K. (2006). Memory and reality. American Psychologist, 61, 760-771.

Johnson, M. K., Hashtroudi, S., \& Lindsay, D. S. (1993). Source monitoring. Psychological Bulletin, 114, 3-28.

Johnson, M. K., \& Raye, C. L. (1981). Reality monitoring. Psychological Review, 88, 67-85.

Johnson, M. K., Raye, C. L., Foley, H. J., \& Foley, M. A. (1981). Cognitive operations and decision bias in reality monitoring. American Journal of Psychology, 94, 37-64.

JonEs, T. C., \& JACOBY, L. L. (2001). Feature and conjunction errors in recognition memory: Evidence for dual-process theory. Journal of Memory \& Language, 45, 82-102.

Kensinger, E. A., \& Schacter, D. L. (1999). When true memories suppress false memories: Effects of aging. Cognitive Neuropsychology, 16, 399-415.

Kinlstrom, J. F. (2004). An unbalanced balancing act: Blocked, recovered, and false memories in the laboratory and clinic. Clinical Psychology: Science \& Practice, 11, 34-41.

KIM, H., \& CABEZA, R. (2007a). Differential contributions of prefrontal, medial temporal, and sensory-perceptual regions to true and false memory formation. Cerebral Cortex, 17, 2143-2150.

KIM, H., \& CABEZA, R. (2007b). Trusting our memories: Dissociating the neural correlates of confidence in veridical versus illusory memories. Journal of Neuroscience, 27, 12190-12197.

Kimball, D. R., Smith, T. A., \& Kahana, M. J. (2007). The fSAM model of false recall. Psychological Review, 114, 954-993.

Koriat, A., Goldsmith, M., \& PAnsky, A. (2000). Toward a psychology of memory accuracy. Annual Review of Psychology, 51, 481-537.

Koutstaal, W., \& Schacter, D. L. (1997). Gist-based false recogni- tion of pictures in older and younger adults. Journal of Memory \& Language, 37, 555-583.

Koutstaal, W., Schacter, D. L., Verfaellie, M., Brenner, C., \& JACKSON, E. M. (1999). Perceptually based false recognition of novel objects in amnesia: Effects of category size and similarity to category prototypes. Cognitive Neuropsychology, 16, 317-341.

Kubota, Y., Toichi, M., Shimizu, M., Mason, R. A., Findling, R. L., Yamamoto, K., \& Calabrese, J. R. (2006). Prefrontal hemodynamic activity predicts false memory: A near-infrared spectroscopy study. NeuroImage, 31, 1783-1789.

Lampinen, J. M., Ryals, D. B., \& Smith, K. (2008). Compelling untruths: The effect of retention interval on content borrowing and vivid false memories. Memory, 16, 149-156.

LAws, K. R., \& BHATt, R. (2005). False memories and delusional ideation in normal healthy subjects. Personality \& Individual Differences, 39, 775-781.

LofTus, E. F. (2005). Planting misinformation in the human mind: A 30 -year investigation of the malleability of memory. Learning \& Memory, 12, 361-366.

Loftus, E. F., \& Pickrell, J. E. (1995). The formation of false memories. Psychiatric Annals, 25, 720-725.

LövdÉn, M. (2003). The episodic memory and inhibition accounts of age-related increases in false memories: A consistency check. Journal of Memory \& Language, 49, 268-283.

Lövdén, M., \& Johansson, M. (2003). Are covert verbal responses mediating false implicit memory? Psychonomic Bulletin \& Review, 10, 724-729.

Lyle, K. B., \& Johnson, M. K. (2006). Importing perceived features into false memories. Memory, 14, 197-213.

Madigan, S., \& Neuse, J. (2004). False recognition and word length: A reanalysis of Roediger, Watson, McDermott, and Gallo (2001) and some new data. Psychonomic Bulletin \& Review, 11, 567-573.

Mather, M., Henkel, L. A., \& Johnson, M. K. (1997). Evaluating characteristics of false memories: Remember/know judgments and memory characteristics questionnaire compared. Memory \& Cognition, 25, 826-837.

McCabe, D. P., Presmanes, A. G., Robertson, C. L., \& Smith, A. D. (2004). Item-specific processing reduces false memories. Psychonomic Bulletin \& Review, 11, 1074-1079.

McCAвE, D. P., \& Smith, A. D. (2002). The effect of warnings on false memories in young and older adults. Memory \& Cognition, 30, 10651077.

McDermott, K. B. (1996). The persistence of false memories in list recall. Journal of Memory \& Language, 35, 212-230.

McDermott, K. B. (1997). Priming on perceptual implicit memory tests can be achieved through presentation of associates. Psychonomic Bulletin \& Review, 4, 582-586.

McDermott, K. B., \& Watson, J. M. (2001). The rise and fall of false recall: The impact of presentation duration. Journal of Memory \& Language, 45, 160-176.

McDermott, K. B., Watson, J. M., \& Ojemann, J. G. (2005). Presurgical language mapping. Current Directions in Psychological Science, 14, 291-295.

McEvoy, C. L., Nelson, D. L., \& Komatsu, T. (1999). What is the connection between true and false memories? The differential roles of interitem associations in recall and recognition. Journal of Experimental Psychology: Learning, Memory, \& Cognition, 25, 1177-1194.

MCNALLY, R. J. (2003). Recovering memories of trauma: A view from the laboratory. Current Directions in Psychological Science, 12, 32-35.

McNally, R. J., Clancy, S. A., Barrett, H. M., \& Parker, H. A. (2005). Reality monitoring in adults reporting repressed, recovered, or continuous memories of childhood sexual abuse. Journal of Abnormal Psychology, 114, 147-152.

McNally, R. J., \& Geraerts, E. (2009). A new solution to the recovered memory debate. Perspectives on Psychological Science, 4, 126134.

McNally, R. J., Lasko, N. B., Clancy, S. A., Macklin, M. L., PitMAN, R. K., \& ORR, S. P. (2004). Psychophysiological responding during script-driven imagery in people reporting abduction by space aliens. Psychological Science, 15, 493-497.

Meade, M. L., Watson, J. M., Balota, D. A., \& Roediger, H. L., III (2007). The roles of spreading activation and retrieval mode in pro- 
ducing false recognition in the DRM paradigm. Journal of Memory \& Language, 56, 305-320.

Melo, B., Winocur, G., \& Moscovitch, M. (1999). False recall and false recognition: An examination of the effects of selective and combined lesions to the medial temporal lobe/diencephalon and frontal lobe structures. Cognitive Neuropsychology, 16, 343-359.

Meyersburg, C. A., Bogdan, R., Gallo, D. A., \& McNally, R. J. (2009). False memory propensity in people reporting recovered memories of past lives. Journal of Abnormal Psychology, 118, 399-404.

Miller, M. B., \& Wolford, G. L. (1999). Theoretical commentary: The role of criterion shift in false memory. Psychological Review, 106, 398-405.

Multhaup, K. S., \& Conner, C. A. (2002). The effects of considering nonlist sources on the Deese-Roediger-McDermott memory illusion. Journal of Memory \& Language, 47, 214-228.

Munsterberg, H. (1908). On the witness stand: Essays on psychology and crime. New York: Doubleday, Page \& Co.

Neuschatz, J. S., Benoit, G. E., \& Payne, D. G. (2003). Effective warnings in the Deese-Roediger-McDermott false-memory paradigm: The role of identifiability. Journal of Experimental Psychology: Learning, Memory, \& Cognition, 29, 35-41.

Neuschatz, J. S., Payne, D. G., Lampinen, J. M., \& Toglia, M. P. (2001). Assessing the effectiveness of warnings and the phenomenological characteristics of false memories. Memory, 9, 53-71.

Palmer, J. E., \& Dodson, C. S. (2009). Investigating the mechanisms fueling reduced false recall of emotional material. Cognition \& Emotion, 23, 238-259.

Park, L., Shobe, K. K., \& Kinlstrom, J. F. (2005). Associative and categorical relations in the associative memory illusion. Psychological Science, 16, 792-797.

Parker, S., Garry, M., Engle, R. W., Harper, D. N., \& Clifasefi, S. L. (2008). Psychotropic placebos reduce the misinformation effect by increasing monitoring at test. Memory, 16, 410-419.

Payne, D. G., Elie, C. J., Blackwell, J. M., \& Neuschatz, J. S. (1996). Memory illusions: Recalling, recognizing, and recollecting events that never occurred. Journal of Memory \& Language, 35, 261285.

Payne, J. D., Schacter, D. L., Propper, R. E., Huang, L., Wamsley, E. J., TUCKER, M. A., ET AL. (2009). The role of sleep in false memory formation. Neurobiology of Learning \& Memory, 92, 327-334.

Pérez-Mata, M. N., Read, J. D., \& Diges, M. (2002). Effects of divided attention and word concreteness on correct recall and false memory reports. Memory, 10, 161-177.

Pesta, B. J., Murphy, M. D., \& Sanders, R. E. (2001). Are emotionally charged lures immune to false memory? Journal of Experimental Psychology: Learning, Memory, \& Cognition, 27, 328-338.

Peters, M. J. V., Horselenberg, R., Jelicic, M., \& Merckelbach, H. (2007). The false fame illusion in people with memories about a previous life. Consciousness \& Cognition, 16, 162-169.

Peters, M. J. V., Jelicic, M., HaAs, N., \& Merckelbach, H. (2006). Mild executive dysfunctions in undergraduates are related to recollecting words never presented. International Journal of Neuroscience, 116, 1065-1077.

Peters, M. J. V., Jelicic, M., Verbeek, H., \& Merckelbach, H. (2007). Poor working memory predicts false memories. European Journal of Cognitive Psychology, 19, 213-232.

Peters, M. J. V., Smeets, T., Giesbrecht, T., Jelicic, M., \& MerckELBACH, H. (2007). Confusing action and imagination: Action source monitoring in individuals with schizotypal traits. Journal of Nervous \& Mental Disease, 195, 752-757.

PEZDEK, K., \& LAM, S. (2007). What research paradigms have cognitive psychologists used to study "false memory," and what are the implications of these choices? Consciousness \& Cognition, 16, 2-17.

Pierce, B. H., Gallo, D. A., Weiss, J. A., \& Schacter, D. L. (2005). The modality effect in false recognition: Evidence for test-based monitoring. Memory \& Cognition, 33, 1407-1413

Platt, R. D., Lacey, S. C., Iobst, A. D., \& Finkelman, D. (1998). Absorption, dissociation, and fantasy-proneness as predictors of memory distortion in autobiographical and laboratory-generated memories. Applied Cognitive Psychology, 12, S77-S89.

PoHL, R. F. (2004). Introduction: Cognitive illusions. In R. F. Pohl (Ed.),
Cognitive illusions: A handbook on fallacies and biases in thinking, judgment, and memory (pp. 1-20). Hove, U.K.: Psychology Press.

Porter, S., Birt, A. R., Yuille, J. C., \& Lehman, D. R. (2000). Negotiating false memories: Interviewer and remember characteristics relate to memory distortion. Psychological Science, 11, 507-510.

Qin, J., Ogle, C. M., \& Goodman, G. S. (2008). Adults' memories of childhood: True and false reports. Journal of Experimental Psychology: Applied, 14, 373-391.

Reysen, M. B., \& Nairne, J. S. (2002). Part-set cuing of false memories. Psychonomic Bulletin \& Review, 9, 389-393.

Robinson, K. J., \& RoEdiger, H. L., III (1997). Associative processes in false recall and false recognition. Psychological Science, 8, 231237.

Roediger, H. L., III (1996). Memory illusions. Journal of Memory \& Language, 35, 76-100.

Roediger, H. L., III, Balota, D. A., \& Watson, J. M. (2001). Spreading activation and the arousal of false memories. In H. L. Roediger III, J. S. Nairne, I. Neath, \& A. M. Surprenant (Eds.), The nature of remembering: Essays in honor of Robert G. Crowder (pp. 95-115). Washington, DC: American Psychological Association.

Roediger, H. L., III, \& MCDERmotT, K. B. (1995). Creating false memories: Remembering words not presented in lists. Journal of Experimental Psychology: Learning, Memory, \& Cognition, 21, 803-814.

RoEdiger, H. L., III, \& MCDERmotT, K. B. (1996). False perceptions of false memories. Journal of Experimental Psychology: Learning, Memory, \& Cognition, 22, 814-816.

Roediger, H. L., III, \& McDermott, K. B. (2000). Tricks of memory. Current Directions in Psychological Science, 9, 123-127.

Roediger, H. L., III, McDermott, K. B., \& Robinson, K. J. (1998). The role of associative processes in creating false memories. In M. A. Conway, S. E. Gathercole, \& C. Cornoldi (Eds.), Theories of memory II (pp. 187-245). Hove, U.K.: Psychology Press.

Roediger, H. L., III, Watson, J. M., McDermott, K. B., \& Gallo, D. A. (2001). Factors that determine false recall: A multiple regression analysis. Psychonomic Bulletin \& Review, 8, 385-407.

RUGG, M. D. (2004). Retrieval processing in human memory: Electrophysiological and fMRI evidence. In M. S. Gazzaniga (Ed.), The cognitive neurosciences (3rd ed., pp. 727-738). Cambridge, MA: MIT Press.

Salthouse, T. A., \& SiedLecki, K. L. (2007). An individual difference analysis of false recognition. American Journal of Psychology, 120, 429-458.

SCHACTER, D. L. (1995). Memory distortion: History and current status. In D. L. Schacter, J. T. Coyle, G. D. Fischbach, M. M. Mesulam, \& L. E. Sullivan (Eds.), Memory distortions: How minds, brains, and societies reconstruct the past (pp. 1-43). Cambridge, MA: Harvard University Press.

SCHACTER, D. L. (2001). The seven sins of memory: How the mind forgets and remembers. Boston: Houghton Mifflin.

Schacter, D. L., Cendan, D. L., Dodson, C. S., \& Clifford, E. R. (2001). Retrieval conditions and false recognition: Testing the distinctiveness heuristic. Psychonomic Bulletin \& Review, 8, 827-833.

Schacter, D. L., Israel, L., \& Racine, C. (1999). Suppressing false recognition in younger and older adults: The distinctiveness heuristic. Journal of Memory \& Language, 40, 1-24.

Schacter, D. L., Norman, K. A., \& Koutstaal, W. (1998). The cognitive neuroscience of constructive memory. Annual Review of Psychology, 49, 289-318.

Schacter, D. L., Reiman, E., Curran, T., Yun, L. S., Bandy, D., McDermott, K. B., \& Roediger, H. L., III (1996). Neuroanatomical correlates of veridical and illusory recognition memory: Evidence from positron emission tomography. Neuron, 17, 267-274.

SCHACter, D. L., \& SLOtNICK, S. D. (2004). The cognitive neuroscience of memory distortion. Neuron, 44, 149-160.

Schacter, D. L., Verfaellie, M., \& Pradere, D. (1996). Neuropsychology of memory illusions: False recall and recognition in amnesic patients. Journal of Memory \& Language, 35, 319-334.

Schooler, J. W., Bendiksen, M. A., \& Ambadar, Z. (1997). Taking the middle line: Can we accommodate both fabricated and recovered memories of sexual abuse? In M. Conway (Ed.), Recovered and false memories (pp. 251-292). Oxford: Oxford University Press.

Seamon, J. G., Goodkind, M. S., Dumey, A. D., Dick, E., Aufseeser, 
M. S., Strickland, S. E., ET AL. (2003). "If I didn’t write it, why would I remember it?" Effects of encoding, attention, and practice on accurate and false memory. Memory \& Cognition, 31, 445-457.

Seamon, J. G., Lee, I. A., Toner, S. K., Wheeler, R. H., Goodkind, M. S., \& BIRCH, A. D. (2002). Thinking of critical words during study is unnecessary for false memory in the Deese, Roediger, and McDermott procedure. Psychological Science, 13, 526-531.

Seamon, J. G., Luo, C. R., \& Gallo, D. A. (1998). Creating false memories of words with or without recognition of list items: Evidence for nonconscious processes. Psychological Science, 9, 20-26.

Shiffrin, R. M., Huber, D. E., \& Marineldi, K. (1995). Effects of category length and strength on familiarity in recognition. Journal of Experimental Psychology: Learning, Memory, \& Cognition, 21, 267-287.

Slotnick, S. D., \& Dodson, C. S. (2005). Support for a continuous (single-process) model of recognition memory and source memory. Memory \& Cognition, 33, 151-170.

Sмith, R. E., \& Hunt, R. R. (1998). Presentation modality affects false memory. Psychonomic Bulletin \& Review, 5, 710-715.

Starns, J. J., СоoK, G. I., Hicks, J. L., \& Marsh, R. L. (2006). On rejecting emotional lures created by phonological neighborhood activation. Journal of Experimental Psychology: Learning, Memory, \& Cognition, 32, 847-853.

Strack, F., \& Bless, H. (1994). Memory for nonoccurrences: Metacognitive and presuppositional strategies. Journal of Memory \& Language, 33, 203-217.

Thapar, A., \& McDermott, K. B. (2001). False recall and false recognition induced by presentation of associated words: Effects of retention interval and level of processing. Memory \& Cognition, 29, 424-432.

Thomas, A. K., \& Sommers, M. S. (2005). Attention to item-specific processing eliminates age effects in false memories. Journal of Memory \& Language, 52, 71-86.

Toglia, M. P., Neuschatz, J. S., \& Goodwin, K. A. (1999). Recall accuracy and illusory memories: When more is less. Memory, 7, 233-256.

Tulving, E. (1985). Memory and consciousness. Canadian Psychologist, 26, 1-12.

UNDERWOOD, B. J. (1965). False recognition produced by implicit verbal responses. Journal of Experimental Psychology, 70, 122-129.

UnSWORTh, N., \& BREWER, G. A. (2010). Individual differences in false recall: A latent variable analysis. Journal of Memory \& Language, 62, 19-34.

Van Damme, I., \& D'Ydewalle, G. (2009). Memory loss versus memory distortion: The role of encoding and retrieval deficits in Korsakoff patients' false memories. Memory, 17, 349-366.

Wade, K. A., Sharman, S. J., Garry, M., Memon, A., Mazzoni, G., Merckelbach, H., \& Loftus, E. F. (2007). False claims about false memory research. Consciousness \& Cognition, 16, 18-28.

Watson, J. M., Balota, D. A., \& Roediger, H. L., III (2003). Creating false memories with hybrid lists of semantic and phonological associates: Over-additive false memories produced by converging associative networks. Journal of Memory \& Language, 49, 95-118.

Watson, J. M., Bunting, M. F., Poole, B. J., \& Conway, A. R. A. (2005). Individual differences in susceptibility to false memory in the Deese-Roediger-McDermott paradigm. Journal of Experimental Psychology: Learning, Memory, \& Cognition, 31, 76-85.

Westerberg, C. E., \& Marsolek, C. J. (2003). Sensitivity reductions in false recognition: A measure of false memories with stronger theoretical implications. Journal of Experimental Psychology: Learning, Memory, \& Cognition, 29, 747-759.

Whittlesea, B. W. A. (2002). False memory and the discrepancyattribution hypothesis: The prototype-familiarity illusion. Journal of Experimental Psychology: General, 131, 96-115.

Wilkinson, C., \& Hyman, I. E., JR. (1998). Individual differences related to two types of memory errors: Word lists may not generalize to autobiographical memory. Applied Cognitive Psychology, 12, S29-S46.
Winograd, E., Peluso, J. P., \& Glover, T. A. (1998). Individual differences in susceptibility to memory illusions. Applied Cognitive Psychology, 12, S5-S27.

WiXted, J. T., \& StRetch, V. (2000). The case against a criterion-shift account of false memory. Psychological Review, 107, 368-376.

Wright, D. B., Startup, H. M., \& Mathews, S. A. (2005). Mood, dissociation and false memories using the Deese-Roediger-McDermott procedure. British Journal of Psychology, 96, 283-293.

YonelinAs, A. P. (1997). Recognition memory ROCs for item and associative information: The contribution of recollection and familiarity. Memory \& Cognition, 25, 747-763.

YonelinAs, A. P. (2002). The nature of recollection and familiarity: A review of 30 years of research. Journal of Memory \& Language, 46, 441-517.

Zoellner, L. A., FoA, E. B., Brigidi, B. D., \& PrZeworski, A. (2000). Are trauma victims susceptible to "false memories"? Journal of Abnormal Psychology, 109, 517-524.

\section{NOTES}

1. DePrince et al. (2004) argued that the DRM illusion represents a misremembering of the details of an event (i.e., which words were presented in the experiment) and not the false memory of an entirely fabricated event (i.e., people do correctly remember being in the experiment). However, a clean distinction between details and events is tricky, especially if one considers events to be mental constructions. If false memories are more simply defined as the recollection of something that did not happen (cf. Roediger \& McDermott, 1995), then the term false memory is justified for the DRM illusion because (1) the belief that the nonstudied word was in the study list is objectively false and (2) evidence suggests that such beliefs often are based on the subjective experience of recollecting an actual memory. Use of the term false memory does not imply equivalence across all types of false memories or events, nor does it imply any particular psychological process that might give rise to the illusory phenomenology. Those issues need to be settled by empirical research, not terminology.

2 . The probability of falsely recalling a lure when its related list is not studied is practically zero, but the probability of falsely recognizing a lure when its related list is not studied is usually greater than zero, owing to uncontrolled factors. These other errors might also be considered false memories if they are accompanied by the subjective experience of remembering, but this is rare. Also, throughout this review, references to the DRM illusion will refer to both false recall and false recognition, which tend to behave similarly for most variables (but see Dewhurst, Barry, Swannell, Holmes, \& Bathurst, 2007, and McEvoy, Nelson, \& Komatsu, 1999, for two exceptions).

3. Analysis of different quantitative models is beyond the present scope, but note that other models also have been applied to the DRM task, including those based on different kinds of associations (e.g., Kimball, Smith, \& Kahana, 2007; McEvoy et al., 1999; see also Shiffrin, Huber, \& Marinelli, 1995), as well as global matching models based on feature similarity and without a special gist representation (e.g., Arndt \& Hirshman, 1998). The model associated with fuzzy trace theory has been applied most extensively and has separate parameters for activation and monitoring processes (as those terms are used here). However, the present goal is to focus on evidence for specific processes and not to adjudicate between different overarching frameworks or models that do (or do not) incorporate some combination of these underlying processes.

4. Another approach to the generalizability question would be to determine the extent that experimentally manipulated variables affect the DRM illusion and false autobiographical memories in the same way. However, even less work has been done with this approach than with individual differences.

(Manuscript received October 27, 2009; revision accepted for publication March 21, 2010.) 